\title{
El populismo de Fernando Vallejo
}

\author{
Fernando Vallejo's Populism
}

\author{
O populismo de Fernando Vallejo
}

Oswaldo Ortegón Cufiño ${ }^{1}$

Resumen

Desde una visión interdisciplinaria, este trabajo busca reconocer actitudes populistas en la narrativa y el habla de Fernando Vallejo. Se observa cómo el autor y el gramático narrador de sus novelas y film $(1994-2010,2000)$ recurren de forma insistente y unívoca a la difusión de un pensamiento demoledor de la vieja institucionalidad, que funda la nación latinoamericana con estrategias comunicativas provocadoras, autoritarias, afectuosas y mesiánicas que, por lo general, tipifican el discurso populista. En la primera parte se discute el entronque ideológicopolítico de Vallejo con la tradición literaria latinoamericana. En la segunda parte se analiza la forma en la que discurren las estrategias comunicativas que se anotan. Algunas de sus novelas, ensayos y presentaciones públicas constituyen la materia de este trabajo. Al final, se destaca la genialidad del lenguaje vallejiano para articular una extraña forma de encantamiento social que carece de un estilo definido.

Palabras clave: Populismo, lenguaje, estrategias comunicativas, lenguaje provocativo, actitud autoritaria, afecto, actitud mesiánica, discurso populista, Fernando Vallejo.

\section{Abstract}

From an interdisciplinary approach, this paper seeks to highlight populist attitudes in the narrative and speech of Fernando Vallejo. This paper shows how both the author and grammarian narrator of his novels and films $(1994-2010,2000)$ rely persistently and unambiguously in the promotion of a negative notion of the old institutions that founded the Latin American nations. His literature is provocative, authoritative and passionate with messianic communicative strategies that generally typify the populist discourse. The first part of this paper discusses the political ideology of Vallejo in the literary Latin American tradition. The second part analyzes how those noted communicative strategies flow. Some of Vallejo's novels, essays and public speaking are addressed in this paper. In conclusion, the paper highlights intelligence of Vallejian language as it articulates a strange form of social enchantment that lacks a defined style.

Keywords: Populism, language, communication strategies, provocative language, authoritarian attitude, affection, messianic attitude, populist discourse, Fernando Vallejo.

\section{Resumo}

Desde uma visão interdisciplinar, este trabalho busca reconhecer atitudes populistas na narrativa e a fala de Fernando Vallejo. Observa-se como 0 autor e o gramático narrador de suas novelas e filme (1994-2010, 2000), recorrem de forma insistente e unívoca, à difusão de um pensamento demolidor da veja institucionalidade, que funda a nação latino-americana com estratégias comunicativas provocadoras, autoritárias, afetuosas e messiânicas que, pelo geral, tipificam o discurso populista. Na primeira parte se discute o enfoque ideológico político de Vallejo, com a tradição literária latino-americana. Na segunda parte se analisa a forma na que discorrem as estratégias comunicativas que se anotam. Algumas das novelas, ensaios e apresentações públicas do autor, constituem a matéria deste trabalho. Ao final, destaca-se a genialidade da linguagem vallejiano, para articular uma estranha forma de encantamento social que carece dum estilo definido.

Palavras-chave: Populismo, linguagem, estratégias comunicativas, linguagem provocativo, atitude autoritária, afeto, atitude messiânica, discurso populista, Fernando Vallejo.

Artículo recibido el 13 de abril de 2015 y aprobado el 26 de junio de 2015

1 University of Kentucky, Lexington, Estados Unidos. Correo electrónico: oswaldoortegon@gmail.com 
Por su insistente actitud subversiva, la narrativa de Fernando Vallejo es controversial en países como Colombia, todavía reticentes al devenir de la modernidad. En los variados estudios que tratan su obra, la interpretación política es accidental. Se discute de su escritura, por ejemplo, la relación "narrativa y exilio", los efectos sociales de su escandaloso pensamiento, la desmitificación de la historia de la nación, las "rupturas ideológicas y estéticas con el discurso identitario", el factor religioso, la violencia colombiana y sus relaciones con el narcotráfico, asuntos de género, entre otros temas dispersos en la obra del autor que, de una u otra forma, abordan tanto las motivaciones políticas de su escritura como dan cuenta de su recepción y reacciones (Salamanca-León, Díaz Ruiz, Diaconu, Camacho Delgado, Betancourt, 2013) ${ }^{2}$.

Me aúno a esta creciente visión interdisciplinaria sobre Vallejo, para reconocer actitudes populistas en su narrativa y habla. Considero que tanto autor como gramático narrador de sus novelas y film (1994-2010, 2000) recurren de forma insistente y unívoca a la difusión de un pensamiento demoledor de la vieja institucionalidad que funda la nación latinoamericana con estrategias comunicativas provocadoras, autoritarias, afectuosas y mesiánicas que de forma general tipifican el discurso populista. Mientras que en la primera parte discuto el entronque ideológico-político de Vallejo con la tradición literaria, en la segunda analizo el discurrir de las estrategias comunicativas que anoto. Algunas de sus novelas, ensayos y presentaciones públicas constituyen la materia de este trabajo. Destaco al final la genialidad del lenguaje vallejiano para articular una extraña forma de encantamiento social que carece de un estilo definido.

Para un autor como Ernesto Laclau:

El populismo es una categoría ontológica y no óntica. Su significado no puede encontrarse en ningún contenido político o ideológico como medio para describir las prácticas de algún grupo

2 Examino sobre todo la antología: Fernando Vallejo: Hablar en nombre propio. Luz Mary Giraldo y Néstor Salamanca-León (Eds.). Bogotá: Universidad Nacional, Universidad Javeriana, 2013. particular (por eso no es óntica), sino en un modo particular de articulación de cualquier actividad con contenido social, político o ideológico. ${ }^{3}(\mathrm{La}-$ clau, 2005, p. 2)

Desde esta definición observamos del populismo su categoría ontológica que, a diferencia de la óntica, sugiere el estudio del componente que le da forma a la cosa de la cual se habla. Así visto, el populismo es articulador de una actividad hermenéutica con contenido social, como la literatura, que sobre todo en el caso latinoamericano está dotada de amplios contenidos políticos o ideológicos.

En efecto, la mayor parte de la literatura latinoamericana sostiene desde su misma definición un halo populista toda vez que época tras época refleja insolubles conflictos de clases sociales necesitadas de un gran líder o salvador que supla o solucione con su carisma, ideas y modos de acción, la debilidad institucional de las sociedades que se representan ${ }^{4}$. Se trata de continuas crisis que de diferente modo reflejan el tortuoso proceso de transición de estas naciones hacia una modernidad aplazada e híbrida mezclada con imaginarios y utopías. Con abundancia de ejemplos, el escritor latinoamericano ha sido además intelectual e ideólogo. Con Laclau, diría que quiere ser articulador social en pos de altruistas propósitos individuales y sociales. La híbrida presencia del escritor y/o su ficción suple la ausencia de válidas directrices ideológicas visibles en la conflictividad política de muchos de sus relatos.

¿Y cómo ha sido tal articulación social? Según Malvina Guaraglia, primero lo hacía "con la figura de un narrador/escritor identificado con la nación y con el statu quo, comprometido con los valores ilustrados y dispuesto a analizar las distintas partes de la sociedad en su diferencia”, cual pudo ser el caso de

3 "Populism is an ontological and not an ontic category- ie. Its meaning is not to be found in any political or ideological content entering into the description of the practices of any particular group, but in a particular mode of articulation of whatever social, political or ideological contents" (traducción elaborada para el presente artículo).

4 Véase el trabajo de Malvina Guaraglia Pozzo. Literatura y pensamiento político: la construcción del pueblo en la narrativa de denuncia social latinoamericana. Madrid: Consejo Superior de Investigaciones Científicas, 2012. 
Faustino Sarmiento o Esteban Echeverría que buscaron interpretar esos "valores ilustrados". "Ahora", dice la ensayista para referirse a la literatura que se hizo desde finales del siglo xIx, "el narrador/escritor tomará partido por una parte muy concreta y lo hará hablar desde la experiencia de su particularidad en contra de las denostaciones, insensibilidad y exclusiones de que ha sido objeto" (Guaraglia, 2012, p. 78) ${ }^{5}$. Ejemplo de este segundo caso son los trabajos de José Martí, Rómulo Gallegos, Juan Rulfo o Fernando Vallejo que, diría, toman partido de forma directa o figurada contra los insultos, menosprecios y exclusiones sociales sentidos tanto por ellos como por el colectivo que representan. Tanto en la actitud política de estos autores como en el sentido de sus obras se observa una infatigable búsqueda de orientación ideológica que determine de otra forma el devenir de sus naciones ${ }^{6}$.

El discurso literario latinoamericano dramatiza la participación del escritor en sociedades carentes de orientación sociopolítica, mediada, en su defecto, por el mercantilismo español e inglés, y luego, por el neoliberalismo de factura norteamericana ${ }^{7}$. Los efectos negativos de la voracidad del capital ahora más globalizado motivan tanto a escritores como a la mayoría de los líderes populistas latinoamericanos a disentir con fiereza contra el crecimiento desmedido y explotador de las sociedades de sus relatos. Por ejemplo, el viejo gramático narrador de La virgen de los sicarios (1994) critica que a Alexis le gusten productos personales y familiares de sonadas marcas extranjeras como tenis de marca "Reebock, jeans Paco Ravan, camisas Ocean Pacific, y ropa interior Kelvin Klein [sic]”. Y en esa misma línea, "las motos Honda, los jeeps Mazda y los refrigeradores Whirpool" de producción foránea. Con este mismo acento continúa la crítica al pobre sistema

5 Martí, José. (1891). Nuestra América.

6 Una buena referencia a este planteamiento lo constituye el trabajo de Javier Lasarte Varcárcel. “Mestizaje y populismo en Doña Bárbara: De Sarmiento a Martí". Iberoamericana, 78 (2000), pp. 164-186.

7 Sobre esta variable de interés económico que acusa modelos de desarrollo social véase: Hernán Vidal. Literatura hispanoamericana e ideología liberal: Surgimiento y crisis. (Un problema sobre la dependencia en torno a la narrativa del boom). Buenos Aires: Hispamérica, 1976. económico cuando referencia "los treinta y cinco mil taxis señalados o (comprados con dólares del narcotráfico porque de dónde va a sacar dólares Colombia si nada exporta porque nada produce como no sea asesinos que nadie compra)" (Vallejo, 1994, pp. 96, 21). Como lo hiciera Rómulo Gallegos con la figura de Mr. Danger en Doña Bárbara (1929), el gramático de La virgen advierte de variadas formas en el contexto de la novela la intrusión norteamericana: destaca, por ejemplo, la amenaza de la lengua por el uso de anglicismos, como la expresión "in the right direction", que remeda del entonces presidente colombiano César Gaviria (1990-1994) cuando quizás daba parte con esa expresión a los gringos de su actividad gubernamental; también, con tono burlesco, intenta adivinar el nombre extranjero que camufla la miseria física y moral de Wílmar, el segundo de sus enamorados: “¿Se llamaba?”, dice, “Tayson Alexander acaso, para variar? Que no. ¿Y Yeison? Tampoco. ¿Y Wílfer? Tampoco" (Vallejo, 1994, p. 34).

Esta crisis ideológica de nuestras naciones, sensible en buena parte de nuestra literatura, manifiesta en el fondo la infecundidad del romance nacional como posible alegoría fundacional de la nación latinoamericana (Sommer, 1993). En nuestra contemporaneidad, este hecho se refleja en obras como La virgen de los sicarios (1994), El desbarrancadero (2001) o Mi hermano el alcalde (2004) de Fernando Vallejo, en las cuales el autor antioqueño reitera la destrucción de esa viciada forma de organización estatal, religiosa y familiar que solo produce sicarios, sidosos y campesinos ignorantes que hoy viven en ciudades ruralizadas, como otrora fueran los "indígenas, gauchos y llaneros" que habitaron "la selva, la pampa o el llano" (Guaraglia, 2012, p. 78). La virgen, por ejemplo, apunta a la destrucción del corrupto mundo existente para que no haya más Alexis ni Wílmars que mueran brutalmente asesinados. El autor continúa la crítica en El desbarrancadero (2001) con el sida de Darío, cual metáfora de la infecciosa enfermedad que aqueja a esa Colombia del relato. Crisis que de otra forma se refleja en $M i$ hermano (2004), relato con propósitos políticos altruistas por parte de una pareja de homosexuales 
en la localidad de Támesis, Antioquia, que tras un buen intento de desarrollo de políticas progresistas, termina en otro fracaso, como el que a su vez narra el viejo y fantasmático narrador de La Rambla paralela (2002) deseoso de rencontrar un mundo que ya no está. De este modo, se cuestionan constantemente en los relatos tanto sistema como régimen político, que de forma entrelazada constituyen a esa nación.

El sistema político lo define Robert Dahl como "todo modelo persistente de relaciones humanas que involucra en un grado significativo control, poder y autoridad" (Dahl, 1983, p. 13). Aspecto que se refleja en la vehemente crítica del gramático vallejiano a la "doctoritis" colombiana. En La virgen, por ejemplo, la figura del "doctor Montoya" es clara demostración de ese "modelo persistente de relaciones humanas" elitistas y excluyentes de origen colonial que de aparente forma inofensiva flotan en el imaginario social. La resonancia al abogado de la ciudad letrada se ve de igual forma en Mi hermano con la figura de Carlos:

"Doctor" le decían pues en efecto era abogado. Allá todos son doctores: los médicos, los ingenieros, los arquitectos, los abogados. Hasta el narcotraficante Pablo Escobar (que en paz descanse) le decían doctor: el doctor Echavarría. ¡Sacaría en Harvard un doctorado en coca! (Vallejo, 2004, 29).

Páginas adelante se retoma la misma crítica en la figura del papá y “yerno" del narrador: “Doctor' le dice (Memo) por respeto pero con cariño. Nosotros también le decimos 'Doctor"', insiste el narrador, al tiempo que alude sarcásticamente el valor de la palabra doctor con su mención a Harvard y Escobar, como opuestos puntos de referencia de marcada significación social (Vallejo, 2004, p. 118).

Si el sistema político sostiene el régimen, este último lo define Maurice Duverger como "un conjunto de instituciones políticas funcionando en un país dado, en un momento determinado" (Durveger, 1984, p. 33). La crisis del régimen político del país de los relatos de Vallejo se refleja en la crítica que realizan los diferentes narradores vallejianos a las instituciones que los representan. El gramático de $L a$ virgen, por ejemplo, le pide al "Señor Fiscal General o Procurador o como se llame" que "con las atribuciones que le dio la Constitución" lo proteja. Esta mención luego se extiende a la histórica figura del Primer Mandatario, una vez que Alexis sintoniza una alocución televisada de "el presidente [quien] el otro día se estaba rasgando las vestiduras el maldito dizque porque unos sicarios habían matado a un senador de la República" que el gramático odia porque está(n) "saqueándome a mí, Colombia, el país entero". Más adelante lo vuelve a nombrar para quejarse del "defensor del pueblo" que instituyó la nueva Constitución que convocó el "bobo marica"; menciona además y con sarcasmo a "nuestro presidente Barco, el inteligente, que nos gobernó cuatro años con el mal de Alzheimer y su secretario el doctor Montoya" (Vallejo, 1994, pp. 20, 36, 43).

En El desbarrancadero, por su parte, critica la avaricia de la familia de la Loca: "si hubiéramos estado robando en el gobierno, como Samper, no habríamos tenido tantas economías, [...] miento, el ladrón no fue Samper, fue López, López Michelsen que se especializó en México" (Vallejo, 2001, pp. 8, 36, 76-77). Mi hermano parodia un intento familiar por hacer política honesta en un país destrozado por la anarquía y denuncia, sin tapujos, a quienes el narrador considera responsables. Por un lado, los guerrilleros Tirofijo, el Mono Jojoy, Raúl Reyes y Romaña; por otro, Pastrana que "fue un desastre para Colombia" y "el marica Gaviria que apadrinó la última Constitución para salvarle los intereses de Pablo [Escobar]". En síntesis, señala que "la roya y la broca de Colombia" (las plagas del café, producto nacional) "son el partido conservador y el partido liberal" representados por esos dos ex presidentes "en concubinato con la Iglesia". Los amigos y familiares de Carlos, candidato a alcalde del relato, sentencian con preocupación que tanto los paramilitares como el reducto de narcotraficantes del cartel de Medellín constituyen otra amenaza para sus aspiraciones políticas (Vallejo, 2004, pp. 20,35, 42, 33, 15) ${ }^{8}$.

8 Las citas se refieren a los ex presidentes César Gaviria (1990-1994), Virgilio Barco (1986-1990) y su secretario privado Germán Montoya. También a los ex presidentes de Colombia Ernesto Samper (19941998), Alfonso López Michelsen (1974-1978) y Andrés Pastrana (1998-2002). Los guerrilleros con sus alias son: “Tirofijo" Manuel 
Estas sarcásticas alusiones del gramático vallejiano engloban buena parte de la institucionalidad que representa el régimen político colombiano: la Nueva Constitución Política, los presidentes de Colombia (asociados ahora con los de México por mantener el mismo viciado modelo presidencialista), el Congreso, la Procuraduría, la Fiscalía y la Defensoría del Pueblo, todas ellas entidades incompetentes e incapaces para administrar deseosa paz y anhelado progreso. Se despliega así una crítica a los serios problemas de gobernabilidad de regímenes que acusan profundas crisis heredadas de la Colonia.

El punto de convergencia ideológico entre el populismo de destacados líderes del continente como Getulio Vargas (1882-1954), Jorge Eliécer Gaitán (1903-1948), Juan Domingo Perón (18851974), Hugo Chávez (1954-2013) o Evo Morales (1959) y el que examinamos en Fernando Vallejo consiste en desterrar a toda costa esa vieja institucionalidad causante de los males que han aquejado a sus naciones. A cambio, esperan el florecimiento de la felicidad anidada en la vívida historia de sus propios pueblos a quienes acuden e increpan de forma directa, como de otra forma creemos lo hace tanto Vallejo como su gramático narrador. Así, el narrador vallejiano añora para sus conciudadanos la arcadia generadora del deseo en una Santa Anita perdida, que de otra forma hace eco al cielo, a La Mancha, a Macondo o a la Santa María de Juan Carlos Onneti9. Es decir, tanto escritores como líderes populistas han expresado con su lenguaje el encuentro con utópicos mundos perfectos, visibles en el delirio que alimenta la fuerza del deseo.

Marulanda Vélez (1930-2008), el guerrillero más viejo del mundo y jefe máximo de las FARC; el "mono jojoy" es Víctor Julio Rojas (19532010), sanguinario miembro de las FARC; "Raúl Reyes" fue Luis Edgar Devia (1948-2008); y alias "Romaña" es Henry Castellanos.

9 En una lectura de Gino Germani (1971), Carlos de La Torre distingue tres momentos de emergencia populista en Latinoamérica causados por "la crisis que provoca la transición hacia la modernidad": "populismo clásico" (Perón, Vargas, Cárdenas), "neopopulismo neoliberal" (Menen, Fujimori, y Collor) y "populismo radical" (Chávez, Morales y Correa). Véase: "Populismo, ciudadanía y Estado de derecho". El retorno del pueblo: populismo y nuevas democracias en América latina. Enrique Perozzoti y Carlos de La Torre (Eds.). Quito: Flacso, 2008, p. 25.
Con sus particulares formas de habla, unos y otros, como diría Carlos de La Torre, parecen portadores de "una misión mítica" (2013, p. 172). Al comienzo de La virgen, por ejemplo, el gramático narrador cita con añoranza a la finca Santa Anita, donde, dice, "transcurrió mi infancia" (Vallejo, 1994, p. 5). En el resto de sus trágicos relatos continúa la nostálgica evocación de esa simulación del cielo. De ahí que como el mesías del relato bíblico, ese gramático re-ordenador del mundo de todas las novelas destruye al hombre viejo que representa esa viciada institucionalidad de la nación colombiana para que surja otro nuevo. De cierta forma es una pelea entre el bien y el mal, entre pobres y ricos: maniqueo asunto político por antonomasia, visible de otra forma en las visiones de mundo que ofrecen los líderes populistas. Para el caso de Vallejo, se trata de un modelo de bien representado en un pensamiento liberal de avanzada, como el que predica el gramático vallejiano, y el mal encapsulado en el viejo establishment que constriñe y excluye. En general, los populistas arguyen que en el libre ejercicio de la autonomía de sus pueblos reside la felicidad de la patria.

En adición a estos presupuestos ideológicos comunes en gran parte de la narrativa latinoamericana, el discurso vallejiano exhibe una estrategia narrativa que lo distancia del establishment literario y le da distinción. Destacamos tanto el híbrido estilo narrativo de sus relatos como la excentricidad del autor y de su gramático narrador. Estas características narrativas y personales permiten el desarrollo de actitudes autoritarias, provocadoras, mesiánicas y afectuosas que, diríamos, facilitan el performance de una voz de talante populista.

De su híbrido estilo narrativo la crítica precisa que "no es ni novela, ni historia, ni poesía, ni biografía", o que busca "sumar la ficción y la realidad, la historia y la imaginación, la narración y el ensayo, la novela y la autobiografía" (Montoya, 2012; Villena, 2009 , p. 14). Como el yo narrador del poema "Yo persigo una forma..." (1896) de Rubén Darío, este escritor antioqueño parece "perseguir (o) una forma que no encuentra su (mi) estilo", lo que supone el 
desarrollo de una forma excéntrica de escribir que corre de la mano con su pensamiento y personalidad (Tapscott, 1996, p. 33).

En efecto, la reiterada crisis de los mecanismos de representación literaria enmarcada en la denominada posmodernidad, permite a escritores como Vallejo el desarrollo de un texto heteroglósico con base en la campechana habla antioqueña. Se trata de una pretensiosa forma de escritura que mientras recoge el sentir de un pueblo excluido conformado por heterogéneos grupos sociales, facilita a autor y alter ego el despliegue de una actitud mesiánica y autoritaria. La fijación social de Vallejo por su pueblo (con invocaciones públicas como "A las madrecitas de Colombia" y "A los muchachitos de Colombia"), encamina su búsqueda de sentido en un incesante ejercicio de experimentación lingüística donde el gramático narrador de sus novelas destruye en cada una de estas el viejo ideario de nación construido por históricos político-gramáticos de una patria reconocida desde sus inicios como $\mathrm{Boba}^{10}$. A cambio se autoinstituye él como nueva voz representativa y autorizada de esos desposeídos. De ahí que en actitud mesiánica precise: "Señor Procurador: Yo soy la memoria de Colombia y su conciencia y después de mí no sigue nada. Cuando me muera aquí sí que va a ser el acabose, el descontrol" (Vallejo, 1994, p. 20).

La autopersonificación de Colombia que asume ese gramático convertido en la voz del pueblo guarda relación con la forma como se instaura la representación populista. Según Carlos de La Torre, esta "asume una identidad de intereses entre el pueblo y su líder, autoerigido como el símbolo y la encarnación de la Nación" (De La Torre, 2008, p. 122). El "soy la memoria de Colombia y su conciencia y después de mí no sigue nada" encierra esa simbología. Actitud mesiánica que se observa mejor

10 Los textos en referencia: Vallejo, Fernando. (Febrero de 2005). "A las madrecitas de Colombia", Soho. "A los muchachos de Colombia". Vallejo, Fernando. (Alocución pública agosto de 2002). Peroratas. Madrid: Alfaguara, 2013. Sobre la importancia de este aspecto del lenguaje en la obra del autor véase: Ospina, María. (2015). “Los embelecos de la gramática: lengua, literatura y herejías gramaticales en la obra de Fernando Vallejo". Cuadernos de literatura, 37, pp. 247-273. en La virgen, relato herético apocalíptico de fin de milenio que por tradición hace eco a la emergencia de salvadores ${ }^{11}$. De ahí que ese gramático narrador se valga de Alexis, el Ángel Exterminador, para que acabe con "basuqueros, buseros, mendigos, policías, ladrones, médicos y abogados, evangélicos y católicos, niños y niñas, hombres y mujeres, públicas y privadas, de todo probó el Ángel” (pp. 108-109). Es decir, el viejo establishment sintió la rabia de ese Ángel Exterminador: "mi niño" dice el viejo, "era el enviado de Satanás que había venido a poner orden en este mundo con el que Dios", el de la historia, "no puede" (Vallejo, 1994, p. 105). Y para que se note la fuerza de esa voluntad divina que encarna ese gramático, se autofaculta para profetizar sobre el nuevo mundo de libertad que anuncia en su prédica.

De ahí que con exceso de ironía use el dialecto madrileño de las traducciones bíblicas para criticar la procreación irresponsable de los pobres: "Pues una cosa sí os digo desventurados. [...] ¿Estáis de acuerdo con heredarles semejante mal a vuestros propios hijos?" (p. 109). Con esta forma de parodia sacra, el gramático asume el papel de un dios castigador con los que siguen funcionando a la luz de esa vieja historia, y a su vez, padre amoroso para quienes deciden seguirlo ${ }^{12}$. Es decir, desacraliza la historia de fuerte componente religioso que sostiene a esa sociedad para que emerja la voz del pueblo, o voz de Dios, a la postre, personificado en ese "último gramático de Colombia”, como se autodenomina el narrador de La virgen. Este, en otra demostración de tal simbolismo vocifera que "no puede andar con menos que con una mini-Uzi para su protección personal [...] En este oeste..." (Vallejo, 1994, p. 51). De ahí la ambigua relación del gramático de esta novela con la figura de Alexis: por un lado, el viejo narrador ama a ese(os) muchachito(s) que por obra de esa historia colombiana no logra(n) ser uno como él, y por otro lado, lo azuza y le compra

11 El lector interesado en explorar la emergencia de profetas en la Edad Media puede consultar: Cohn, Norman. (1957). The Pursuit of the Millennium. New York: Oxford University Press.

12 Sobre la parodia sacra véase: Bajtín, Mijaíl. (1988). La cultura popular en la Edad Media y en el Renacimiento. El contexto de Francois Rabelais. Madrid: Alianza. p. 15. 
balas para que acabe hasta con la figura presidencial de esa Colombia. Es un morir para volver a nacer.

El mesianismo que surge de la híbrida habla vallejiana surte igualmente una combinación de autoridad y afecto $^{13}$. Son visiones de mundo paternalistas de sonora actitud populista que se reflejan en la mayoría de sus trabajos. En Vallejo, se trata de una expresión de autoridad político-moral que de varias formas se arroga y expresa tanto gramático narrador en sus novelas como autor en sus ensayos. Si el gramático de La virgen asume la vocería del pueblo, símbolo de la voz de Dios, Vallejo en sus ensayos desmitifica la historia, se burla de ella y se autoproclama redentor. Por ejemplo, en la biografía de José Asunción Silva, Chapolas Negras (1995), Vallejo critica el trabajo de destacados gramáticos y latinistas como Miguel Antonio Caro (1845-1909), Rufino José Cuervo (1844-1911), Rafael Núñez (1825-1894) y Baldomero Sanín Cano (1861-1957).

De este último certifica que fue "crítico literario y maestro por excelencia, si algún libertador tiene Colombia es él: no el cobardón granuja de Bolívar hinchado de retórica y pompa y gloria. Baldomero Sanín Cano nos libertó de lo que no pudo el otro: de la mente loca y mentecata de España la católica, la dogmática, roña del espíritu humano" (Vallejo, 1995, 62). Un par de páginas adelante, critica el uso innecesario de perífrasis en la escritura de Sanín Cano e irónicamente dice que "le corrijo esas frasecitas y le doy el título sublime de Libertador" (pp. 65-66). Igual sentencia proyecta con el irónico título $E l$ cuervo blanco (2012), donde Vallejo canoniza, entre otros, a Rufino José Cuervo, gramático de entre los poderosos gramáticos colombianos por su titánico ejercicio en pos de una fracasada organización de la lengua castellana (Vallejo, 2012, pp. 247, 120, 290, 296). No está de más anotar que otros de sus ensayos como La tautología darwinista (1998), Manualito de imposturología física (2004) y La puta de babilonia (2007) desmitifican de forma descarnada visiones

13 Sobre el amor afecto en narrativa vallejiana, véase: Villena Garrido, Francisco. (2009). "Eutanal: representaciones del afecto". En Las máscaras del muerto: autoficción y topografías narrativas en la obra de Fernando Vallejo. Bogotá: Pontificia Universidad Javeriana. tradicionales de la historia. Así, la sentida voz del autor emerge como salvadora.

La autoridad moral que paso a paso deslinda el pensamiento vallejiano adquiere mayor funcionalidad en el desarrollo del tono autoritario que distingue su retórica. Se trata de una forma de habla popular donde el hablante, cuando se dirige a su contertulio, lo increpa para tratar de adivinarle sus posibles respuestas. Ejercicio lingüístico que configura la lógica de la ironía luego que fuerza al otro, al escucha, a responder como el hablante monólogo espera. A su vez, establece una relación jerárquica de dominio que va del hablante al escucha. Por ejemplo, luego de reconocer la voz popular de que Medellín es también llamada "Medallo" y/o "Metrallo", el gramático de La virgen insiste en esta ironía: “¿Qué si tiene el país cosas buenas?" Y se responde: "Pero claro, lo bueno es que aquí nadie se muere de aburrición. Va uno de bache en bache desquitándole al atracador y al gobierno" (1994, pp. 47-48). El gramático narrador detona en la mente del lector una explosión de imágenes conocidas, al mismo tiempo que jalona el hilo del discurso. Esta forma comunicativa favorece el desarrollo de una voz autoritaria, intimidatoria y demandante que, diríamos, engancha e hipnotiza al lector predispuesto en principio al abordaje de una animada historia de ficción, como se observa en $\mathrm{La}$ virgen con un globo "de ciento veinte pliegos, rojo, rojo, rojo para que resaltara sobre el cielo azul. El tamaño no me lo van a creer. ¡Pero qué saben ustedes de globos! ¿Saben qué son?” Con un previo halo de ingenuidad el gramático narrador vallejiano toma al lector de la mano para en apariencia narrarle una infantil historia de globos sobre el cielo azul.

Luego que lo ha puesto a pasearse por ese imaginario, ausculta su credibilidad y lo reprende de forma despreciativa y casi humillante: “Pero qué saben ustedes de globos!" Y de inmediato lo reconviene: “¿Saben qué son?”. Esta forma de encantar al oyente lector para cuestionarlo y redirigir su atención simula el trabajo del hipnotizador. Éste, como cualquier destacado líder populista, se instituye desde el principio en el centro de atención intimidando afectuosamente a su cliente o elector para 
que se entregue y quede a merced de su admirado predicador. En ciega actitud, éste será quien decida su destino. No en vano, destacados líderes populistas como Adolfo Hitler, Getulio Vargas, Hugo Chávez o Juan Domingo Perón fueron militares o figuras autoritarias que subvirtieron sus anacrónicos sistemas políticos con encantadoras proclamas de aire celestial. Una vez estos personajes se convierten en el centro de atención de sus pueblos, la frontera entre la demagogia y el sometimiento se difumina. Perón, por ejemplo, no dudó en expresarlo:

Le hemos dado al pueblo argentino la oportunidad de elegir, en las elecciones más libres y honestas de la historia argentina, entre nosotros y nuestros adversarios. El pueblo nos ha elegido, por lo tanto ese dilema está solucionado. En Argentina, se hace lo que decidimos. (Peruzzotti, 2008, p. 19) ${ }^{14}$

Actitud intimidatoria y a su vez demandante se observa de otra forma en La virgen, cuando el gramático ocupa la desafiante posición del sicario. Por ejemplo, molesto por la música ruidosa en taxis de Medellín, exige:

"Así que me va apagando ese radio, señor taxista, que hoy no ando pa discusiones". Y santo remedio, lo apagaban. Algo oían en mi tono de perentorio, la voz de Thánatos, que les quitaba toda gana de disentir: o lo apagaban o lo apagaban. (Vallejo 1994, p. 51)

En otra ocasión, después de un crimen callejero, exige lo mismo:

$\mathrm{Y}$ apague el loro que venimos supremamente ofuscados. Se lo dije en uno de esos tonos que he cogido que no admiten réplica, y dócil, sumiso, vil, lo apagó. (Vallejo 1994, p. 57)

Así, ese gramático se convierte para el lector en su objeto de atención o, parafraseando a Freud, en ese "yo ideal" que lo guía en el reconocimiento del discurso que sostiene su histórica tragedia. Sin miedo, ese héroe lleva al lector de la mano por ese

14 Véase: Peruzzotti, Enrique. (2008). “Populismo y representación democrática". Carlos de la Torre y Enrique Peruzzotti (Eds.). El retorno del pueblo. El populismo y nuevas democracias en América Latina. Quito: Flacso, p. 109. mundo sicaresco/dantesco del discurso narrativo para que lo acompañe en la destrucción de sus causas: el binomio religión católica y política que construyó una forma excluyente de hablar. En este sentido, subvierte instituciones fundacionales como la familia patriarcal, la Iglesia y esa vieja estructura estatal para implantar otra donde reine la libertad y la pureza del amor. Propuesta contra-institucional, de apariencia demagógica y de cierta manera mítica que en la realidad funciona solo como aventura del deseo. De otro modo, podría entenderse como "significantes vacíos" de clásico reconocimiento en el discurso populista debido a que solo arrogan fatuas esperanzas.

En el habla vallejiana no basta la protesta de un contra-gramático del tradicional modelo de sociedad. Visiones de mundo con propósitos similares abundan en nuestra historia literaria. Mejor diríamos que en Vallejo prevalece una actitud subversiva que además escandaliza, produce pánico moral e instiga a la acción debido a que tanto autor como personaje encausan un juego de espejos a veces indiferenciable para el lector carente de experiencia literaria. En efecto, gracias al magistral uso de la ilusión mimética en sus obras literarias y film (como La virgen de los sicarios [2000]), autor y personaje se confunden en un símbolo de escandalosa rebeldía, lo que provoca controvertibles reacciones como la del editorialista de la Revista Diners y hoy embajador de Colombia en Portugal, Germán Santamaría, en noviembre del año 2000. Para Santamaría, quien es también escritor, tanto la película La virgen de los sicarios como el discurso público de Vallejo en el Parque Nacional de Bogotá con motivo del Encuentro Iberoamericano de Escritores de ese mismo año, constituyen una afrenta contra Colombia. Dijo el editorialista de Fernando Vallejo:

Vino al encuentro de escritores de Bogotá por un salario de cinco mil dólares, recibió atenciones de cinco estrellas, solo para lanzar una de las diatribas más siniestras contra Colombia. Les exigió a todos los colombianos abandonar el país, les pidió que no se reprodujeran más y en su mensaje, dirigido 
"a los muchachitos de Colombia", lanzó lo que es su imaginario de escritor y lo puso en la boca del Presidente de la República: “iMaten, roben, extorsionen, destruyan, secuestren, pero eso sí, háganlo a cabalidad para que se queden con lo que quede de Colombia!". En visitas anteriores pidió incluso bombardear a Colombia. (2000).

Esta actitud sediciosa de Fernando Vallejo la describen de otra forma, escritores como Elena Poniatowska (1932) y Carlos Monsiváis (19382010). Mientras que para la autora de Hasta no verte Jesús mío (1969), Vallejo "es por voluntad propia un gran [o verdadero] provocador", para Monsiváis, el autor antioqueño:

No tiene reparo a decir las cosas políticamente incorrectas $[\ldots]$ riesgosas $[. .$.$] en un tono suave,$ tranquilo $[\ldots]$ es una suerte de pastel envenenado $[\ldots]$ en un tono dulce $[\ldots]$ que permite que las cosas más atroces para los oyentes sucedan sin violentarlo acústicamente, pero con una gran carga de tensión o presión ideológica. (Poniatowska y Monsiváis, en Ospina, 2005, pp. 105-116).

Cínica actitud sostenida a lo largo de sus obras que de otra forma el autor reconoce en posteriores obras como El don de la vida (2010) donde el gramático personaje recuerda una experiencia sexual de sus años juveniles: "Para esa Colombia, que escupe a la felicidad y me mira como a un paria, mi tesoro de esa noche era uno entre muchos" (Vallejo, 2010, p. 10).

Si en su discurso del Parque Nacional, Vallejo le pide a esos muchachitos que: "Maten, roben, extorsionen, destruyan, secuestren" ${ }^{15}$, el viejo gramático narrador de La virgen azuza a Alexis y Wílmar, sus sicarios enamorados con quienes por cierto se siente uno, ("somos" dice) para que de otra forma hagan lo mismo, como se observa en el enojo del gramático por la presencia en televisión del presidente: "Si querés te quiebro a esa gonorrea", le pregunta Alexis, a lo que el gramático le replica: “广Y cuándo vas a quebrar

15 Véase: Ospina, Luís. (2005). Retrato incesante de Fernando de Vallejo. Ministerio de Cultura, Bogotá, Videocasete. Minutos 10508 . El texto dentro del corchete corresponde a las palabras de Poniatowska en el mismo sentido que se anota. la casetera?" "Ya", le responde Alexis (Vallejo, 2013, p. 17; 1994, pp. 38, 34). Es decir, por momentos, el contenido y tono del discurso se hace indiferenciable por una clara ilusión de transferencia o mimetismo de la voz del autor en sus obras y film. Este ejercicio narrativo da pie a la emergencia de una voz no solo provocadora sino estridente que mantiene al lector embelesado a lo largo de todas sus novelas, como la de $E l$ don que abre la narración con desafiante pregunta: “¿Quién tiene la verga más grande en este bar de maricas? Pregunté al entrar todo borracho, y me trajeron un muchacho" (Vallejo, 2010, p. 9).

Esta constante provocación y desafío de Vallejo contra toda forma de institucionalidad $u$ orden existente, llámense ideas fundacionales de nación, régimen político y sistema político, Iglesia católica, cristianismo, islamismo, gobierno o academias de la lengua, da pie a la emergencia de un Vallejo autoritario, gánster del lenguaje que dispara e intimida como lo hacen sus Alexis. Pero, además, es una estrategia narrativa que degrada una forma de organización social excluyente que desconoce el derecho a la existencia de la diferencia. De ahí esa falsa agresividad al comienzo de $\mathrm{El}$ don con la placentera figura del muchacho que más bien busca patentar otras formas de organización social, en las que prime la afluencia del amor. Insistente búsqueda inscrita antes en La virgen, donde el gramático denomina al lector "parcero, [...] compañero, amigo y paisano" como si este fuese ya otro de sus enamorados (Vallejo, 1994, pp. 41, 48). Actitud similar despliega el autor en su discurso del Parque Nacional de Bogotá, cuando según el editorialista de la discordia, le pidió a los muchachitos de Colombia: “Maten, roben, extorsionen, destruyan, secuestren, pero eso sí, háganlo a cabalidad para que se queden con lo que quede de Colombia!". Desde esta hibridez narrativa tanto autor como alter ego destilan una sensible relación de afecto y odio constituida por un amor libidinal, similar al que se tejía entre líderes autoritarios como Hitler o Mussolini y la masa que los seguía ${ }^{16}$.

16 Véase: Freud, Sigmund. (2006). “Piscología de las masas y el análisis del yo" (1921). Sigmund Freud. Obras completas. Luís López Ballesteros (Trad.). T. 3. Madrid: Biblioteca Nueva, 2006. 
Las actitudes autoritarias, provocadoras y escandalosas de Vallejo que discutimos proyectan de sí mismo la figura de un Vallejo excéntrico. Su deseo de romper con la historia de la nación colombiana, ejemplo de la latinoamericana, se demuestra no solo en la procacidad de su pensamiento y rústico estilo narrativo, sino en la proyección social de su imagen personal. Él, que no tiene reparos en recusar la historia, rompe con el tradicional esquema de posicionamiento social como escritor e intelectual para inscribirse como personaje excéntrico, incontaminado, es decir, al margen de los habituales centros de atención, como en la práctica se proyectan los más reconocidos líderes populistas: menosprecian la institucionalidad vigente para construir otra nueva fuera de la órbita en la cual giran sus sociedades. Por ejemplo, Hugo Chávez, Evo Morales y Rafael Correa solían o suelen presentarse públicamente vestidos en camisas con diseños extravagantes que aluden a la historia de sus pueblos indígenas en oposición al uso de la corbata de tradición occidental. En este mismo sentido, risibles pronunciamientos públicos como el de Chávez, quien en la Asamblea de las Naciones Unidas llamó a George W. Bush "el diablo", o los desacertados argumentos sobre la calvicie y la homosexualidad de los europeos de parte de Evo Morales, demuestran sus deseos de llamar la atención pública y mantener viva su circulación en la nueva órbita social creada por ellos ${ }^{17}$.

Como estos personajes de la política, diríase que Vallejo es un sujeto a-institucional que mientras descree de modelos sociales instaurados se excede en su posición social como individuo y escritor. Algunas sonadas actuaciones personales fuera de lo común, como por ejemplo, cepillarle los dientes a su perra (según se aprecia en el video de William Ospina), o donar a entidades defensoras de animales el dinero que recibió de los premios Rómulo Gallegos (2003) y FIL (2011), precisan su excentricidad. Si bien podría decirse que Vallejo pertenece a una nueva generación de escritores del llamado pos boom, su

17 El pronunciamiento de Hugo Chávez ocurrió en la Asamblea General de la onu el 20 de septiembre de 2006. El de Evo Morales, en la Primera Conferencia Mundial de Pueblos sobre el Cambio Climático y la Madre Tierra el 20 de abril de 2010. interés principal ha sido auto marginarse, distanciarse o salirse del gremio de los escritores, para en efecto, mantener aún más su independencia y de paso llamar la atención. No formó parte Vallejo, por ejemplo, del Primer Encuentro de Escritores Latinoamericanos que Seix Barral promovió en Sevilla a finales de junio de 2003, cuando su nombre ya alcanzaba reconocimiento ${ }^{18}$.

Con un lenguaje cautivante y demoledor, Fernando Vallejo arrasa con la vieja idea de nación para que surja otra más inclusiva. Propuesta que además de ideológica resulta populista, tanto por el tono revolucionario y agitador de autor y gramático narrador, como por el contenido de la misma. "La esencia del escritor como intelectual", dicen Octavio Paz y Mario Vargas Llosa, "está determinada por el uso creador del lenguaje, lo cual lleva implícita una crítica del lenguaje, que después de todo es el medio que utilizan para el intercambio de ideas" (Santí, 1997, p. 29) ${ }^{19}$. En efecto, creatividad y buen ejercicio del lenguaje distinguen a Fernando Vallejo como escritor e intelectual finisecular. Se trata de una literatura que, además de conservar el principio revolucionario de todas las buenas literaturas, incita a la acción. De ahí que voces como la de Óscar Collazos en el "Espectáculo Vallejo", señalen que al escritor antioqueño "lo aplaudan(en) los extremistas de izquierda cuando se mete con el Estado, el gobierno, el Presidente de la República o el Papa" (Collazos, 2006).

Una de las características más singulares de la narrativa vallejiana es su pretensiosa singularidad, aspecto que de cierta forma contrasta con la categoría ontológica del populismo que anota Ernesto Laclau: su obediencia a "un modo particular de

18 La lista de asistentes al acto estuvo compuesta por: Roberto Bolaño, Jorge Franco, Rodrigo Fresán, Santiago Gamboa, Gonzalo Garcés, Fernando Iwasaki, Mario Mendoza, Ignacio Padilla, Edmundo Paz Soldán, Cristina Rivera Garza, Iván Thays y Jorge Volpi.

19 Para plantear esta idea, Enrico Santí elabora una larga discusión a la luz de los postulados de Gramsci y Foucault sobre la posición del escritor latinoamericano asumiendo posiciones de derecha 0 de izquierda, característico de los convulsionados años ochenta cuando el mundo acusaba un alto grado de bipolaridad política. Santí, Enrico Mario. Por una politeratura. Literatura latinoamericana e imaginación política. México, D.F.: Ediciones El Equilibrista, 1997. Impreso. 
articulación [...] con contenido social, político o ideológico" (Laclau, 2003, p. 2) ${ }^{20}$. Tanto Vallejo como su gramático narrador asumen una visible actitud revolucionaria directa con el pueblo (del cual entra a formar parte su lector), a quien mantiene atónito remarcándole de una y otra forma su diatriba contra institucional. Posmoderna forma literaria de narrar que de cierto modo se asimila a la actuación populista: carece de un estilo definido en cuanto a las formas tradicionales de hacer política. Esa estratégica rareza facilita el enganche del líder con el pueblo. De otro modo diríamos que tanto en la literatura de este autor antioqueño como en el actuar populista parece existir, como dijera el "yo" narrador del poema de Rubén Darío que anotamos, la "persecución de una forma que no encuentra su estilo" ${ }^{21}$. O mejor, eficaz aunque indescriptible forma de comunicar, debido, entre otros aspectos, a la sensible carga afectiva que esas autoritarias formas de habla contienen. Paradójico aspecto comunicacional que destacaba Óscar Collazos: "el autor de El desbarrancadero, un tipo amable y tierno en el trato personal se puso a interpretar un papel ante los medios de comunicación y ha tenido que seguir siendo fiel al personaje construido" (Collazos, 2006).

Un habilidoso juego del lenguaje por parte del autor resulta fundamental en el ejercicio literario que desarrolla. Genialidad que no solo demuestra con su hacer narrativo sino que reconoce literalmente y con otro propósito en El Cuervo blanco: El "genio del idioma", dice Vallejo, "no se deja meter en una botella como los de Las mil y una noches" y por ser "inmenso y escurridizo, se burla de las categorías y terminologías de los gramáticos, y de paso de la lógica porque no es lógico sino eficaz" (Vallejo, 2013, p. 267). En la búsqueda de esa eficacia comunicativa, la narrativa vallejiana "se burla de las categorías y terminologías de los gramáticos" tradicionales, “y de paso de la lógica" institucional que durante siglos le

20 Texto del cual traduzco al español la cita completa: “Populism is an ontological and not an ontic category- i.e. Its meaning is not to be found in any political or ideological content entering into the description of the practices of any particular group, but in a particular mode of articulation of whatever social, political or ideological contents".

21 "Persigo", dice ese narrador del autor nicaragüense. ha dado forma a la nación colombiana. En ese propósito acude a una novedosa estrategia comunicativa que fundamenta en un híbrido estilo narrativo donde un excéntrico gramático narrador, alter ego del autor, encarna la voz del pueblo para levantarse contra la historia.

De este modo resaltamos con Laclau la característica que mejor distingue al populismo: esa asimetría o modo particular de articulación que genera la estratégica relación directa que surge entre el líder y el pueblo favorecida por el uso heteroglósico y emotivo que, a su modo, cada líder hace del lenguaje. La eficacia comunicativa se impone a la lógica tradicional del discurso.

\section{Referencias}

Baktin, M. (1988). La cultura popular en la Edad Media y en el Renacimiento. El contexto de Francois Rabelais. Madrid: Alianza.

Betancourt, J. D. (2013). Fernando Vallejo: una nota queer en la narrativa colombiana. En. L. M. Giraldo y N. Salamanca (Eds.), Fernando Vallejo. Hablar en nombre propio. Bogota: Universidad Javeriana y Universidad Nacional.

VV. AA. (2004). Palabra de América. Barcelona: Seix-Barral.

Camacho Delgado, J. M. (2013). Fernando Vallejo y el pensamiento herético en La puta de Babilonia. En L. M. Giraldo y N. Salamanca (Eds.), Fernando Vallejo. Hablar en nombre propio. Bogotá: Universidad Javeriana y Universidad Nacional.

Cohen, S. (1972). Folk Devils and Moral Panics. The Creation of the Mods and Rockers. New York: St. Martin's Press.

Cohn, N. (1970). The Pursuit of the Millennium. New York: Oxford University Press.

Collazos, O. (02 de noviembre de 2006). El espectáculo de Vallejo. El Tiempo.

Dahl, R. (1983). Análisis político actual. Buenos Aires: Eudeba.

Darío, R. (1996). Yo persigo una forma... (1896). En S. Tapscott (Ed.),Twenty-Century Latin American Poetry. A Bilingual Anthology. Austin, Texas: The University of Texas Press. 
Diaconu, D. (2013). Colombia linda y Espana castiza. En L. M. Giraldo y N. Salamanca (Eds.), Fernando Vallejo. Hablar en nombre propio. Bogotá: Universidad Javeriana y Universidad Nacional.

Díaz Ruiz, F. (2007). Fernando Vallejo y la estirpe inagotable del escritor maldito. Caravelle: Cahiers du monde hispanique et luso-brésilien. 89: 231-248.

Díaz Ruiz, F. (2009). La virgen de los sicarios o el apocalipsis de Colombia según Vallejo. Los imaginarios apocalípticos en la literatura hispanoamericana contemporánea. Oxford: Peter Lang.

Duverger, M. (1961/2012). Los partidos políticos. México, D.F.: Fondo de Cultura Económica.

Guaraglia Pozzo, M. (2012). Literatura y pensamiento político: la construcción del pueblo en la narrativa de denuncia social latinoamericana. Madrid: Consejo Superior de Investigaciones Científicas.

Freud, S. (1921/2006). Sigmund Freud. Obras completas (Piscología de las masas y el análisis del yo. Trad. de Luis López Ballesteros. Tomo 3). Madrid: Biblioteca Nueva.

Laclau, E. (2005). Populism: What's in a Name? Francisco Panizza (Ed.). Populism and The Mirror of Democracy. London: Verso.

Lasarte Varcárcel, J. (2000). Mestizaje y populismo en Doña Bárbara: De Sarmiento a Martí. Iberoamericana 78:164-186.

Martí, J. (1891). Nuestra América.

Montoya, P. (2012). Fernando Vallejo: Demoliciones de un reaccionario. Ómnibus, 40.

Ospina, L. (2005). Retrato incesante de Fernando de Vallejo. Bogotá: Ministerio de Cultura [videocasete].

Ospina, M. (2015). Los embelecos de la gramática: lengua, literatura y herejías gramaticales en la obra de Fernando Vallejo. Cuadernos de literatura. 37, 247-273.

Peruzzotti, E. (2008). Populismo y representacion democrática. En C. de la Torre y E. Peruzzotti (Eds.), El retorno del pueblo: populismo y nuevas democracias en América latina. Quito: Flacso.

Salamanca-Leon, N. (2013a). Pater familias paradiso expulsos. En L. M. Giraldo y N. Salamanca (Eds.), Fernando Vallejo. Hablar en nombre propio. Bogotá: Universidad Javeriana y Universidad Nacional.

Salamanca-León, N. (2013b). Escritura y exilio en La Rambla paralela.En L. M. Giraldo y N. Salamanca (Eds.), Fernando Vallejo. Hablar en nombre pro- pio. Bogotá: Universidad Javeriana y Universidad Nacional.

Santamaría, G. (6 de noviembre del 2000). Prohibir al sicario. Semana.

Santí, E. M. (1997). Por una politeratura. Literatura latinoamericana e imaginación política. México, D.F.: El Equilibrista.

Sommer, D. (1993). Foundational Fictions. The National Romances of Latin America. Berkeley: University of California Press.

Tapscott, S. (Ed). (1996). Twentieth-Century Latin American Poetry: A Bilingual Anthology. Austin: University of Texas Press.

Torre, de la, C. (2008). Populismo, ciudadanía y Estado de derecho. En C. de la Torre y E. Peruzzotti (Eds.), El retorno del pueblo: populismo y nuevas democracias en América latina. Quito: Flacso.

Vallejo, F. (1994). La virgen de los sicarios. Madrid: Punto de Lectura.

Vallejo, F. (1995). Chapolas negras. Bogotá: Santillana.

Vallejo, F. (1998). La tautología darwinista. Santa Fe de Bogotá: Taurus.

Vallejo, F. (2001). El desbarrancadero. Bogotá: Alfaguara. Vallejo, F. (2002). La Rambla paralela. Bogotá: Alfaguara. Vallejo, F. (2004). Mi hermano el alcalde. Bogotá: Alfaguara.

Vallejo, F. (2004). Manualito de imposturología física. Bogotá: Taurus.

Vallejo, F. (Febrero de 2005). A las madrecitas de Colombia. Soho.

Vallejo, F. (2007). La puta de Babilonia. México, D.F.: Planeta.

Vallejo, F. (2010). El don de la vida. Bogotá: Alfaguara. Vallejo, F. (2012). El cuervo blanco. Madrid: Alfaguara.

Vallejo, F. (Agosto de 2002). A los muchachos de Colombia. (Alocución pública). Peroratas. Madrid: Alfaguara.

Vidal, H. (1976). Literatura hispanoamericana e ideología liberal: Surgimiento y crisis. (Un problema sobre la dependencia en torno a la narrativa del boom). Buenos Aires: Hispamérica.

Villena Garrido, F. (2009). Las máscaras del muerto: autoficción y topografías narrativas en la obra de Fernando Vallejo. Bogotá: Pontificia Universidad Javeriana. 